on the side of the smaller instrument is more common than it is generally supposed to be. With me, at least, it is the rule; and so, to relieve the bladder in cases of enlarged prostate, I should take first an instrument of full size with an ordinary curve, or a curve not exceeding the quadrant of a circle two inches or so in diameter.

\section{On the Treatment of Stricture of the Urethra.}

It may be well from time to time to call attention to the still prevalent practice of treating all cases of stricture of the urethra by the introduction of instruments. I say all cases; for when a stricture has been once made out, does it ever escape bougies? How many cases occur of contraction due to spasm or to temporary thickening of the membrane from inflammation or congestion, w:-hich if left alone would speedily clear up, but which are worried into permanent stricture by such mischievous activity? Even when organic or permanent stricture is established, how very seldom does it come under the notice of the surgeon uncomplicated by inflammation or congestion and spasm? and are these conditions to be subdued by the employment of instruments? Is this in accordance with any recognised principle in surgery? Many cases of so-called stricture need no instrumental interference from first to last, and by such means are only made worse ; and of those cases in which muoh may be done at the proper stage by the judicious use of instruments, there are very few indeed which do not require, for some time previously and simultaneously, treatment in the way of rest and other measures to subdue the active mischief, which in ordinary circumstances is almost invariably associated in some degree with passive structural contraction. The story is well known of a physician who, having in consultation discovered pericarditis, consoled his colleague who had overlooked it with the reflection, "My dear fellow, if you had found it out you would have treated it." How far the ordinary treatment would have been bad for the pericarditis I cannot say; but I am sure that stricture of the urethra sometimes suffers very much at the hands of surgery from being found out; and, unfortunately, it has but little chance of escape in the way of being overlooked; In every case, of course, instruments must be passed, and the existing evil is not only apt to be thus aggravated when present, but too often it is nursed into existence.

\section{ON CASES OF BACILLI IN SCARLET FEVER. ${ }^{1}$}

BY GEORGE F. CROOKE, M.B. ED., RESIDENT MEDICAL OFFICER, LEEDS FEVER HOSPITAL.

THE bacilli figured in the accompanying woodcut were found in the nasal discharge and in the sero-purulent exuda. tion from the inflammatory lymphatic tissue of the neck in certain cases of scarlet fever.

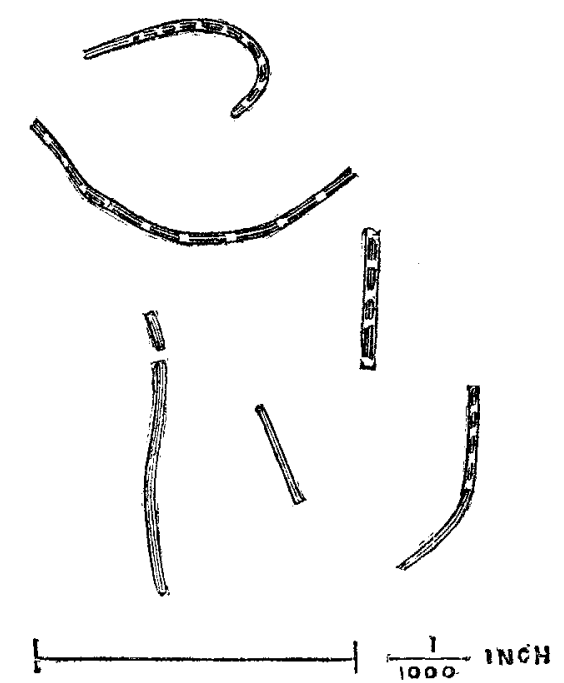

CASE 1, which I will relate because it represents fairly well the type of the subsequent ones in which bacilli were also found, was that of a previously healthy child, four years of age, admitted last autumn on the third, and dying on the

1 Being the substance of a communication to the Leeds and West Riding Medico-Chirurgical Society, read Feb. 2nd, 1883. fourteenth, day of the fever. From its commencement the attack was very severe, and the following are some of the chief symptoms that were observed up to its fatal termination :-A persistent high temperature, which underwent a further elevation just before death, reaching $106^{\circ} \mathrm{F}$.; great restlessness and delirium; rash characteristic and well out, but of rather darker hue than usual; injection and swellivg of fauces, uvula, and tonsils, the latter ulcerated on their inner aspects; much naso-pharyngeal catarrh, with pofise sero-purulent discharge of a rather offensive slour-indecd, there seemed to be a general offensive smell emanating from the patient; the cervical lymphatic olunds were con siderably involved even at this early stage, both sides of the neck being lumpy, but the right more than the left ; vomiting was more or less frequent, there was severe diarrhœa, and the urine was slightly albuminous. One point of clinical interest in the case was the inflammatory condition of the lymphatic glands and tissues of the neck. The swelling gradually increased until it reached that peculiar brawny condition by no means rare in severe cases of scarlet fever. The skin over it was tense and shining, its consistence boggy and semi-elastic, but no fluctuation indicating abscess formation could be felt. I incised the swelling a few days before death, and was struck with the character of the exudation from the wound. It was a turbid, dirty-reddish serum, of offensive odour, and the swelling was seen to be due to an extensive gelatinous infiltration of the tissues of the neck. I at once took some of the exudation on the point of the knife, spread it between two cover-glasses, which I afterwards dried and stained according to Koch's method with gentian violet, mounting them in balsam. My examination of the slides was, I regret to say, only a cursory one, for my attention was occupied with numerous cases of fever in the hospital. But I labelled the slides, and put them away for future examination, which I have made only within the last month or two. On examining the slides with high powers, I found numerous bacilli, as represented in the woodcut; but I will defer their description, and proceed to relate a few other recent cases in which I have found apparently the same organism. For convenience sake $I$ will number them $2,3,4$, and 5. Clinically all suffered severely from throat symptoms, much nasal catarrh and discharge, considerable swelling of the neck, and constitutional disturbance of a more or less severe form.

CASE 2 died on the thirteenth day of the fever, and the internal condition of the throat, together with the externainflammatory swelling of the neck, necessitated the operal tion of tracheotomy. She was one whose nasal discharge I examined the day after her admission (third day of disease), and found the bacillus-the long, transverse, curved, and segmented one figured in the woodeut. An offensive odour was noticed about her a day or two after admission; and it was further observed that when the constitutional symptoms ran high the nas̃al discharge was more profuse, more watery and offensive. I examined some of this fresh watery secretion, and found the bacillus in abundance, but apparently quiescent. I also examined the blood in this case taken trom the puncture of a miuute venule, and prepared dried specimens of it according to Koch's method. Bacteria are to be seen-viz., isolated cocci (spores?), the bacterium termo, and small short rods (bacilli); but I could not find anything like the fully developed bacillus seen in the nasal discharge. Immediately after death I examined the swelling of the neck, and found the lymphatic glands and the tissue round about welded into a greyish-red succulent-looking mass, but I could find no traces of purulent infiltration or softening. There were red vascular spots which looked as if they might have broken down had the disease gone on longer. I prepared slides of scrapings from this tissue, placing other portions into alcohol for section-cutting. In all the slides I found bacilli, but they were not so abundantly distributed as in the slides prepared from the first case. In one very good slide it was quite numerous in certain foci. I hope shortly to proceed with the more detailed examination of the organs and inflamed glands of this patient.

CASE 3 (sister to Case 2), at present in the hospital, but in a critical condition, gave the bacillus from the nasal discharge, which has been rather profuse the last three or four days.

CASES 4 and 5 are sisters who have had a severe attack with profuse nasal discharge in which the bacillus was found.

In Case 5 the inflammation of the neck went on to 
abscess, which I opened, evacuating bloody and thick curdy pus. I examined this, and found the chain micrococcus in abundance but no bacilli.

The bacillus may be described as leptothrix-like filaments, some straight, some curved, and other's bent at an angle, varying in length from $\frac{1}{1000}$ in. to 10100 in., breadth about 40000 in. ; some show rod segmentation very distinctly, in others small spore-like bodies are visible, and scattered all about the field are numbers of these spores or cocci. I have never yet found a well-marked zoogloa formation peculiar to the micrococcus; but these cocci, or, I think, spores, are scattered mostly singly or in very small groups all over the field. I have not been able to determine whecher there is a distinct sheath. What I took, with dry objectives, to be a sheath, I believe now to be due to diffraction lines. With an excellent Zeiss $\frac{1}{3}$ oil immersion, and, still better, with an equally good $\frac{1}{16}$ oil immersion recently forwarded to me by M. Prazmowski, of Paris, I was able, in a few of the bacilli, to make out a faintly stained basis substance of a mucoid character, in which the darkly stained rods and cubical spores were seen to lie. I am not yet prepared, however, to undertake to distinguish this bacillus by its microscopical appearances from every other bacillus, for we know that the various bacilli which of late have been figured and written about-viz., the anthrax bacillus, the bacillus subtilis, leptothrix, the bacillus of pneumo-enteritis of the pig-all resemble each other in general characters, their differences being mainly as to size and character of spores. The bacillus $I$ have described and figured is certainly remarkable for its minuteness, the woodcuts of which were copied from draw ings with the camera under a magnifying power of 1100 diameters. As regards length, they are quite correct, but are if anything, a shade broader than they actually appeared under that magnifying power.

What $I$ do lay stress upon is the apparent microscopical identity of the bacillus found in the nasal discharge of the patients with that found in the lymph from the inflamed glands and tissues of the necks of two of them. It is suf. ficient to encourage further researches in this direction, and I hope other workers with similar opportunities in the same field will before long be able to record the result of their observations. The only check observations I have as yet been able to make are in connexion with enteric fever and coryza. In the sputum of the former I found a few filaments of leptothrix, which resembles very much the bacillus from the scarlet fever cases, but is certainly larger; in the nasal secretion from typhoid I could get nothing but the ubiquitous micrococcus in zooglœa formation. In coryza $I$ found cocci in the nasal discharge (of the acute stage), but no trace of bacillus. I myself had a pretty acute coryza, and as I am constantly moving about in an atmosphere of germs, I thought I should most likely find the bacillus, and perhaps I ought to feel comforted with the result of my investigations-namely, that my nasal cavity did not appear to be a suitable nidus for the organism to settle in, notwithstanding the inflammatory condition of the mucous membrane, which is generally supposed to be a condition favourable for the implantation of germs.

I may be asked whether I have examined the urine of scarlet fever patients for the organism lately described as being found there; and in answer to that query I should have to reply practically in the negative. Such observations on the urine of fever patients in a fever hospital must be conducted with great precautions, but in future investiga. tions I shall include the examination of the urine, though feeling a little sceptical as to the results to be obtained. I remember a short time ago examining microscopically a specimen of slightly sanguinous and albuminous urine an hour after it was passed by a scarlet fever patient, and I found it literally swarming with active rod-shaped bacteria, much larger, as far as I can remember, than the ones in the drawing, for they were easily discernible with a power of 250 diameters. The only explanation that I could think of was that the urine had been passed into a utensil containing a residuum of stale urine. The nurse, however, assured me it was passed direct into a urine glass which had just previously been scalded out with boiling water and dried. I should state that I had found organisms in the same urine four hours after it was passed, and in this next observation told the nurse to be careful to get a perfectly clean utensil to receive it, and I have no doubt my instructions were carried out. This, then, is the only time I found organisms in the urine of a scarlet fever patient, in the third week, at a time when the pyrexia and constitutional disturbance had subsided ; and the explanation of their presence still remains to me a niystery.

Lately, M. L. Bel announced his discovery of the bacillus of measles in the urine of patients suffering from that disease, and about the same time Dr. C. Burger, of Bonn, found in pertussis its special bacillus in the sputum. I have had no opportunity of searching for these organisms as yet, but from the description given of them, while there may be some semblance of the measles bacillus with those I have obtaiued from scarlet fever, yet the elliptical shape of the whooping-cough bacillus is sufficient to distinguish it. With regard to the nasal discharge in scarlet fever patients, it seems, from a clinical note upon a case communicated to the British Medical Jounnal of Feb. 3rd, by Dr. Tinley of Whitby, to possess considerable infective properties It appears from his very interesting communication that boy suffering from scarlet fever, and treated in a feve hospital, was discharged apparently quite well and free from infectiousness after eight weeks' isolation. About a week after returning home, he appeared to have a distinct relapse, and it was noticed that, in addition to a fresh sorethroat, ulceration was going on in the nose. Within three days a brother and a sister sickened and developed the fever, and the source of their infection admits of no other explana. tion than from their brother, who was discharged as convalescent from the hospital, but evidently with mischief still going on in the nasal cavities. It would indeed have been interesting to have examined the nasal discharge from this lad for the bacilli I have described.

I have to thank Dr. Jacob, the visiting physician to the hospital, for his courtesy in placing his cases at my disposal, and also my friend Mr. James Abbott, of, this town, whose practical knowledge of microscopy was of great assistance to me when looking over the slides with higher powers.

P.S -I should mention that the staining fluid used was quite fresh and carefully examined for organisms with negative results, and that similar precautions were taken in using clean slides and cover-glasses.

Leeds.

\section{A GROUP OF EIGHT CASES OF CANCER OF THE RECTUM.}

SUCCESSFUL COLOTOMY IN FIVE; SUCCESSFUL PARTIAL EXCISION OF THE RECTUM IN ONE; TWO NOT OPERATED ON ; REMARKS.

BY ARTHUR E. BARKER, F.R.C.S. ENG., ASSISTANT PROFESSOR OF CLINICAL SURGERY AT UNIVERSITY COLLEGE AND ASSISTANT SURGEON TO UNIVERSITY COLLEGE HOSPITAL.

(Concluded from p. 31/.)

CASE 5. - R. M- aged thirty-four, admitted under my care on July 28th, 1882. He had been a very strong man, but when first seen, five weeks before admission, he had an expression of much suffering, standing with his back bowed down and his hands resting on his knees, the latter slightly flexed, complaining of intense gnawing pain down his legs as low as the ankles. His face was pale and haggard from want of sleep for a long time. His family history was good, both parents being alive and aged seventy-two, and hereditary cancer distinctively negatived. About five months before melæna and pain on defecation were noticed; his motions, which often reached twenty a day, consisting of almost pure blood at times. When first seen before admission, found a new growth encircling the bowel just within reach of the finger, its upper margin being only accessible during anæsthesia; it appeared about an inch deep, was rugged, ulcerated, bled slightly, and was extremely painful to the touch. The mass seemed generally movable, but much less so behind, where it appeared more or less fixed to the sacrum. Other efforts to give relief having failed, the patient became anxious for any operation which would afford him relief from his intolerable suffering. As he was young, generally bealthy, and the growth had only appeared comparatively recently, and was still limited, I hoped to be able to excise it completely as in Case $2 .{ }^{1}$ But there was some doubt in my mind whether it could be reached as easily, and also whether it was not to some extent extend- 